\title{
PENGARUH REAL EARNINGS MANAGEMENT DAN CORPORATE GOVERNANCE TERHADAP CORPORATE ENVIRONMENTAL DISCLOSURE
}

\author{
Lia Resti Pratiwi ${ }^{1}$, Kurniawan ${ }^{2}$ \\ Universitas Matana ${ }^{1,2}$ \\ E-mail: kurniawan@matanauniversity.ac.id
}

\begin{abstract}
This study aims to examine real earnings management and corporate governance on corporate environmental disclosure. Real earnings management variables using the approach of Stubben (2010). This study uses 10 companies in the 2014-2017 period. The sample selection method uses non probability sampling method with purposive sampling technique. Data were analyzed using the classic assumption test, descriptive statistics, and moderate regression analysis using SPSS 24. The results of this study prove that real earnings management and corporate governance with a number of boards of commissioners no effect to corporate environmental disclosure., while the board of commissioners and the relationship of independent commissioners effect to corporate environmental disclosure.
\end{abstract}

Keywords: real earning management, corporate governance, corporate environmental disclosure.

\section{Pendahuluan}

Perusahaan tambang di Indonesia masih memiliki kesadaran rendah terhadap dampak pencemaran lingkungan. Misalnya saja pencemaran lingkungan di sungai-sungai Bengkulu akibat pertambangan batubara yang dilakukan dengan pertambangan terbuka di lokasi konsesi yang banyak berada pada wilayah daerah aliran sungai (Ardiansyah, 2014). PT Indominco Mandiri di Kutai Kartangera, Kalimantan Timur, juga melanggar tindak pidana lingkungan, dengan mencemari lingkungan karena pembuangan limbah berbahaya, dari operasi PLTU di Desa Santan Tengah dan Desa Santan Ilir, Kecamatan Muarangkayu (WALHI 2018). Selain informasi banyaknya perusahaan tambang yang tidak sadar terhadap lingkungan, ada juga perusahaan tidak melakukan kewajiban membayar jaminan reklamasi dan jaminan paska tambang. Data Yayasan Genesis dan Jaringan Advokasi Tambang (Jatam) Nasional tahun 2016 menunjukkan, dari 12 perusahaan pertambangan di Bengkulu hanya 8 perusahaan tambang batubara yang menunaikan kewajiban membayar jaminan reklamasi dan paska tambang. Kewajiban pembayaran jaminan reklamasi dan paska tambang sangat penting dipergunakan untuk penataan lahan kembali akibat dari kegiatan operasi pertambangan dan mengembalikan kawasan hutan sesuai fungsinya. Kewajiban itu diatur UU No 4/2009 tentang pertambangan mineral dan batubara. Lingkungan hidup menjadi peran penting bagi perusahaan tambang, karena dalam proses kegiatan usahanya mengunakan sumber daya alam terus menerus dan berakibat pencemaran lingkungan.

Pentingnya pengungkapan lingkungan bagi entitas ekonomi tidak hanya images yang baik di masyarakat tetapi dapat sebagai pertimbangan manfaat secara entitas keuangan (Mirela et al., 2014). Pengungkapan lingkungan hidup diatur dalam Pernyataan Standar Akuntansi Keuangan (PSAK) no 1 (revisi 2013) paragraf empat belas yaitu beberapa 
perusahaan juga menyajikan laporan tambahan di dalam laporan keuangan yaitu laporan mengenai lingkungan hidup khususnya bagi perusahaan yang dalam usahanya lingkungan hidup memegang peran penting. Pernyataan PSAK tersebut menjelaskan bahwa laporan tambahan mengenai lingkungan hidup belum wajib dan disampaikan secara sukarela oleh perusahaan. Implementasi corporate environmental disclosure di Indonesia sampai saat ini masih belum memenuhi harapan dilihat dari masalah-masalah diatas, serta pengungkapan tersebut masih bersifat sukarela sehingga hanya sedikit perusahaan yang terdaftar yang mengungkapkan informasi sosial dan lingkungan dalam laporan tahunan mereka. Oleh karena itu penerapan corporate environmental disclosure memerlukan komitmen yang kuat untuk mewujudkannya.

Manajemen akan mempertimbangkan corporate environmental disclosure dilihat dari sisi biaya dan manfaat yang akan diperoleh perusahaan (Anggraini, 2006). Pertimbangan tersebut adanya dorongan kepentingan antara manajemen (agent) dan pemilik (principal) untuk mengoptimalkan semua kegiatan usaha untuk mendapat keuntungan yeng lebih besar. Dorongan tersebut memaksa manajer melakukan tindakan oportunis atas kebijakan pelaporan penghasilan agar laporan pendapatan perusahaan terlihat lebih baik dari sebenarnya seperti real earnings management.

Murwaningsari (2009) menjelaskan bahwa manajemen baik dilihat dari pengawasan, control, serta transparantsi dan akuntabel sebagai pertanggungjawaban sosial perusahan atas semua pelaporan terhadap steckholders, konsep tersebut biasa disebut konsep corporate governance. Penerapan corporate governance paling penting adalah dewan komisaris, karena dewan komisaris sebagai puncak pengawan tertinggi di dalam perusahaan. Pengungkapan Corporate Governance sebagai laporan tambahan perusahan memberikan dampak positif terhadap penilaian perusahan secara berkelanjutan, dewan komisaris memiliki peran penting dalam penerapan Corporate Governance. Berdasarkan UU Nomor 40 tahun 2017, dewan komisaris adalah orang perusahaan yang mempunyai tugas memberi pengawasan seacara umum dan/atau khusus dengan anggaran dasar serta memberi nasehat kepada direksi sesuai pendoman umum dari tata kelola perusahaan yang baik di Indonesia. Perusahaan yang memiliki mekanisme dan struktur governance dapat mengurangi asimetri informasi antara manajemen dengan steckholders.

Berdasarkan uraian diatas, Tujuan penelitian ini, yaitu : (a). mengetahui dan membuktikan real earnings management memiliki pengaruh terhadap corporate environmental disclosure, (b). mengetahui adanya pengaruh corporate governance yang diproksikan dengan dewan komisaris, proporsi dewan komisaris independen dan rapat dewan komisaris terhadap corporate environmental disclosure.

\section{Tinjauan Literatur dan Pengembangan Hipotesis}

Teori Agensi, Menurut Jensen dan Meckling (1976) bahwa keagensian mengambarkan hubungan antara manejemen dengan pemilik perusahan, dimana manajemen diberi wewenang dan tanggung jawab oleh pemilik perusahaan diikat dalam suatu kontrak perjanjian bersama. Jika manajer diketahui melakukan kecurangan manajemen laba maka nilai perusahaan akan buruk dan akan mengurangi kesejahteraan prisipal karena biaya yang timbul karena tindakan tersebut (Jensen dan Meckling, 1976).

Corporate environmental disclosure merupakan sinyal yang dapat mengalihkan perhatian pemegang saham dari pengawasan manipulasi laba atau isu-isu lainnya dan sebagai hasilnya harga saham di pasar modal akan meningkat seiring meningkatnya kepercayaan pemegang saham terhadap transparansi informasi yang diungkapkan oleh perusahaan (Sun $e t$ al., 2010). 
Teori Sinyal, Hartono (2005) menjelaskan teori sinyal adalah perusahaan yang memberikan sinyal kepada pasar sebagai perusahaan yang memiliki kualitas baik.sehingga diharapkan pasar dapat membedakan perusahaan yang mempunyai prospek baik maupun buruk.

Gray et al. (1987) menjelaskan bahwa corporate environmental disclosure sebagai salah satu kegiatan good governance merupakan sinyal yang terkait dengan kualitas manajemen. Corporate environmental disclosure memberikan sinyal kepada masyarakat bahwa citra perusahaan baik karena bertanggung jawab terhadap lingkungan.

Teori Stakeholder, tujuan utama dari teori stakeholder adalah untuk membantu manajer korporasi mengerti lingkungan stakeholder mereka dan melakukan pengelolaan dengan lebih efektif di antara keberadaan hubungan-hubungan di lingkungan perusahaan mereka (Deegan, 2004).

Corporate environmental disclosure juga sebagai strategi untuk membina hubungan perusahaan dengan stakeholder melalui pelaporan informasi kinerja perusahaan, aktivitas sosial, dan aktivitas yang berdampak terhadap lingkungan (Ardillah, 2018). Dewan komisaris independen di dalam jajaran dewan komisaris juga sebagai pengawasan dan pengendalian internal yang lebih independen untuk menarik kepercayaan dari stakeholder. Semakin tinggi proporsi dewan komisaris independen akan maningkatkan kepercayaan stakeholder.

Teori Legitimasi, adanya teori legitimasi maka untuk mengurangi gap dengan mencari cara untuk menjamin operasi perusahaan dalam batas normal sesuai aturan (Deegan, 2014). Teori legitimasi dapat membantu perusahaan pertambangan untuk mengurangi gap di masyarakat atas kegiatan usaha yang telah merusak lingkungan hidup dengan cara bertanggungjawab dengan cara menata, memulihkan, dan memperbaiki kualitas lingkungan dan ekosistem agar dapat berfungsi kembali sesuai peruntukannya. Peraturan tersebut juga telah diatur dalam UU No 4 tahun 2009 tentang pertambangan mineral dan batu bara.

Corporate Envormental Disclosure. Pentingnya Corporate environmental disclosure karena masyarakat dapat mengawasi kegiatan yang dilakukan perusahaan dalam memenuhi tanggung jawab sosialnya melalui pengungkapan dalam laporan tahunan perusahaan (Ardillah, 2018).

Corporate environmental disclosure membantu perusahaan memperoleh dukungan para stakeholders untuk mengurangi dampak resiko dari tanggungjawab perusahaan atas lingkungan sehingga memperolah citra baik dimasyarakat dan legitimasi eksternal bisa diperbaiki (Setyawan dan Kamilla, 2015).

Real Earnings Management. Real Earnings Management adalah tindakan atau kebijakan dengan maksud tertentu yang melanggar praktek bisnis pada umumnya dalam proses pelaporan keuangan eksternal dengan tujuan tercapainya laba yang diharapkan (Roychowdhury et al., 2012).

Manipulasi aktivitas real seperti memberikan diskon harga, penurunan pengeluaran diskresioner yang mungkin merupakan tindakan optimal pada kondisi tertentu (Roychowdhury et al, 2012). Menurut Sembiring dan Nahumury, (2018) upaya tersebut dilakukan untuk meningkatkan kinerja jangka pendek dengan mengorbankan nilai perusahaan jangka panjang merupakan trade-off dalam hal keputusan tindakan manipulasi laba aktivitas real.

Corporate Governance. Organisation for Economic Co-operation and Development (2015) menilai corporate governance sebagai sebuah sistem untuk mengarahkan dan mengendalikan perusahaan. 
Dewan Komisaris. Nasution dan Setiawan (2007) menjelaskan dewan komisaris bertugas dan bertanggung jawab untuk memastikan bahwa perusahaan telah melakukan tanggung jawab sosial dan mempertimbangkan kepentingan berbagai stakeholder perusahaan sebaiknya memonitor efektifitas pelaksanaan corporate governance. Menurut Undang-Undang No. 40 Tahun 2007 tentang Perseroan Terbatas, Komisaris adalah organ perseroan yang bertugas melakukan pengawasan serta memberikan nasihat kepada Direksi.

Dewan Komisaris Independen. Di Indonesia ketentuan dewan komisaris independen di dalam perusahaan diatur dalam ketentuan Peraturan Otoritas Jasa Keuangan Nomor 33/POJK.04/2014, dimana setiap perusahaan publik harus memiliki Komisaris Independen sekurang-kurangnya 30\% dari jumlah seluruh anggota dewan komisaris. Secara lebih luas tugas komisaris independen adalah mengawasi dewan direksi perusahaan dalam mencapai kinerja dalam business plan dan memberikan nasihat kepada direksi mengenai penyimpangan pengelolaan usaha yang tidak sesuai dengan arah yang ingin dituju oleh perusahaan (Alijoyo et al., 2004).

Rapat Dewan Komisaris. Rapat Dewan Komisaris merupakan tempat atau waktu untuk berkomunikasi dan berkoordinasi antara anggota dewan komisaris lainnya dalam menjalankan tugasnya sebagai control atau pengawasan didalam manajemen perusahaan (Zaky et al., 2017). Berdasarkan surat edaran Otoritas Jasa Keuangan No. 30 /SEOJK.04/2016 bahwa dalam tata kelola perusahaan pelaporan frekuensi dan tingkat kehadiran dewan komisaris dalam rapat dewan komisaris dilaporan di dalam annual report dalam periode tertentu.

Keterkaitan Real Earnings Management Terhadap Corporate Environmental Disclosure. Manipulasi aktivitas riil ini terjadi selama periode akuntansi dengan tujuan spesifik yaitu tujuan mencapai target pelaporan keuangan tertentu seperti laba yang diharapkan, menghindari kerugian, dan mencapai target analyst forecast (Wisnantiasri dan Narsa, 2014). Manajemen yang melakukan real earnings management menggunakan corporate environmental disclosure sebagai upaya untuk menggalang dukungan dari para stakeholder dan memberikan citra perusahaan kepada masyarakat. Penelitian ini berbeda dengan penelitian Setyorini dan Suranta (2015) menemukan real earnings management yang dilakukan perusahaan pengaruh terhadap pengungkapan tanggung jawab sosial perusahaan. $\mathrm{H}_{1}$ : Real earnings management berpengaruh terhadap corporate environmental disclosure.

Keterkaitan Corporate Governance yang Diproksikan dengan Dewan Komisaris Terhadap Corporate Environmental Disclosure. Frendy (2011) menyatakan corporate governance yang baik dari perusahaan publik di Indonesia mempengaruhi tingkat corporate environmental disclosure. Dewan komisaris sebagai pimpinan tertinggi dari sistem pengelolaan internal perusahaan, memiliki peranan terhadap aktivitas pengawasan operasional perusahaan. Dengan kata lain, dewan komisaris dapat mendorong dewan komisaris untuk bertindak objektif dan mampu melindungi seluruh stakeholder perusahaan sehingga hal ini dapat mendorong pengungkapan corporate environmental disclosure lebih luas. Penelitian Frendy et al. (2011), Effendi (2012) dan Sun, et al. (2010) yang menemukan adanya pengaruh yang signifikan antara dewan komisaris dengan corporate environmental disclosure.

$\mathrm{H}_{2}$ : Corporate governance dengan proksi dewan komisaris berpengaruh terhadap corporate environmental disclosure. 
Keterkaitan Corporate Governance yang Diproksikan Dengan Proporsi Dewan Komisaris Independen Terhadap Corporate Environmental Disclosure. Menurut Haniffa dan Cooke (2005), apabila jumlah komisaris independen semakin besar atau dominan hal ini dapat memberikan power kepada dewan komisaris untuk menekan manajemen untuk meningkatkan kualitas pengungkapan perusahaan. Semakin tinggi proporsi dewan komisaris independen didalam perusahan akan semakin besar kemungkinan perusahaan mendorong pengungkapan corporate environmental disclosure lebih luas. Penelitian Zaky et al. (2017), Sun et al. (2010) dan Effendi et al. (2017) yang menemukan adanya pengaruh yang signifikan antara proporsi dewan komisaris independen dengan corporate environmental disclosure.

$\mathrm{H}_{3}$ : Corporate governance dengan proksi proporsi dewan komisaris independen pengaruh terhadap corporate environmental disclosure.

Keterkaitan Corporate Governance yang diproksikan Dengan Rapat Dewan Komisaris Terhadap Corporate Environmental Disclosure. Menurut Brick \& Chidambaran (2007), dan Effendi et al. (2012) menunjukkan bahwa semakin banyak rapat yang diselenggarakan dewan komisaris akan meningkatkan kinerjanya di dalam perusahaan. Semakin sering dewan komisaris mengadakan pertemuan, maka akrual kelolaan perusahaan menjadi semakin meningkat pula. Sehingga kinerja yang semakin meningkat akan berdampak pada tingkat pengungkapan lingkungan sosial.

$\mathrm{H}_{4}$ : Corporate governance dengan proksi rapat dewan komisaris pengaruh terhadap corporate environmental disclosure.

\section{Metode Penelitian}

Pada penelitian ini mengunakan sumber data sekunder yaitu data yang diperoleh dari sumber yang sudah ada yang diperoleh dari situs resmi Bursa Efek Indonesia (BEI) pada http://www.idx.co.id dan website masing-masing perusahaan sampel. Jenis data penelitian ini mengunakan data kuantitatif yaitu data yang dinyatakan dalam bentuk angka.

Corporate Envormental Disclosure. Pengukuran corporate environmental disclosure dalam penelitian ini mengunakan indek GRI verisi terbaru yaitu G4 telah telah banyak digunakan oleh perusahaan di Indonesia. Penelitian ini mengacu pada penelitian Cooke (1989) yaitu pengukuran corporate environmental disclosure mengunakan skor pengungkapan lingkungan pada annual report dengan indeks GRI. Pengungkapan items environmental disclosure mengunakan GRI-G4 kategori lingkungan total 34 item disclosure, untuk score disclosure digunakan dalam penentuan indek pengungkapan.

Penelitian ini hanya mengunakan kategori lingkungan pada indeks GRI karena hanya khusus untuk meneliti tanggung jawab perusahaan terhadap lingkungan hidup sehingga kategori lain kecuali lingkungan pada indeks GRI tidak digunakan sebagai score environmental disclosure. Perusahaan yang mengungkapkan item informasi akan diberikan score 1. Skala pengukuran yang digunakan dalam mengukur dewan komisaris adalah skala rasio.

$$
\text { Corporate Environmental Disclosure }=\frac{\text { Jumlah itemyang diungkapkan perusah } 2 a n}{\text { Jumlah item pengungkapan lingkungan GRI }}
$$


Variabel Independen. Variable independen dalam dalam penelitian ini adalah real earnings management dan corporate governance diproksikan dengan dewan komisaris, proporsi dewan komisaris independen dan rapat dewan komisaris.

Real Earnings Management. Pengukuran manipulasi laba rill ini diproksikan dengan abnormal cash flows from operating (abnCFO), abnormal production costs (abnPROD), dan abnormal discretionary expenses (abnDISEXP) dengan menggunakan model Roychowdhury et al, (2012). Pengukuran 3 proksi tersebut dengan rumus sebagai berikut:

\section{Abnormal Cash Flows From Operating (Abncfo)}

Roychowdhury et al, (2012) menggambarkan arus kas kegiatan operasi normal sebagai fungsi linear dari penjualan dan perubahan penjualan dalam suatu periode.

$$
\frac{\mathrm{CFO}_{\mathrm{t}}}{\mathrm{A}_{\mathrm{t}-1}}=\alpha_{0}+\alpha_{1} \frac{1}{A_{\mathrm{t}-1}}+\beta_{1} \frac{S_{\mathrm{t}}}{A_{\mathrm{t}-1}}+\beta_{2} \frac{\Delta S_{\mathrm{t}}}{A_{\mathrm{t}-1}}+\mathrm{e}_{\mathrm{t}}
$$

\section{Abnormal Production Costs (Abnprod)}

Produksi di atas level normal operasi perusahaan (overproduction) dengan tujuan untuk melaporkan harga pokok penjualan (COGS) yang lebih rendah merupakan salah satu cara yang dilakukan manajemen untuk memanipulasi laba melalui manipulasi aktivitas nyata (Istianingsih, 2016).

$$
\frac{\text { PROD }_{t}}{A_{t-1}}=\alpha_{0}+\alpha_{1} \frac{1}{A_{t-1}}+\beta_{1} \frac{S_{t}}{A_{t-1}}+\beta_{2} \frac{\Delta S_{t}}{A_{t-1}}+\beta_{3} \frac{\Delta S_{t-1}}{A_{t-1}}+e_{t}
$$

\section{Abnormal Discretionary Expenses (Abndisexp)}

Biaya diskresioner didefinisikan sebagai jumlah dari biaya iklan, biaya riset dan pengembangan, dan biaya penjualan, serta biaya administrasi dan umum (Istianingsih, 2016).

$$
\frac{\text { DISEXP }_{t}}{A_{t-1}}=\alpha_{0}+\alpha_{1} \frac{1}{A_{t-1}}+\beta \frac{S_{t}}{A_{t-1}}+e_{t}
$$

Skala pengukuran yang digunakan dalam mengukur real earnings management adalah skala rasio. Persamaannya rumus sebagai berikut :

$$
\text { REM = AbnCFO *(-1) + AbnDISEXP *(-1) + AbnPROD }
$$

Dewan Komisaris. Pengukuran corporate governance pada dewan komisaris diukur dari Jumlah seluruh anggota dewan komisaris dalam suatu laporan tahunan perusahaan (Waryanto, 2010). Jumlah dewan komisaris dalam perusahaan biasanya dicantumkan pada laporan tata kelola perusahaan ataupun laporan dewan komisaris. Skala pengukuran yang digunakan dalam mengukur dewan komisaris adalah skala nominal.

Proporsi dewan komisaris independen. Proporsi dewan komisaris independen dapat dihitung dengan jumlah komisaris Independen terhadap jumlah seluruh anggota dewan komisaris (Haniffa dan Cokke, 2005). Skala yang digunakan dalam mengukur proporsi 
dewan komisaris independen adalah skala rasio. Model regresi dewan komisaris sebagai berikut:

$$
\text { Proporsi dewan komisaris independen }=\frac{\text { Jumlah anggota komisaris independen }}{\text { jumlah anggota dewan komisaris }}
$$

Rapat dewan komisaris. Pengukurannya adalah jumlah rapat internal yang dilakukan dewan komisaris pada laporan tahunan perusahaan yang tercantum pada laporan tata kelola perusahaan maupun laporan dewan komisaris (Brick dan Chidambaran, 2007). Skala pengukuran yang digunakan dalam mengukur rapat dewan komisaris adalah skala nominal.

\section{Hasil Penelitian dan Pembahasan}

Berdasarkan purposive sampling dari 41 perusahaan pertambangan yang terdaftar di Bursa Efek Indonesia hanya 10 perusahaan pertambangan yang memenuhi kriteria dengan tahun pengamatan yaitu 2014-2017, sehingga diperoleh keseluruhan data berjumlah 40 data.

Statistik Deskriptif. Analisis statistik deskriptif dalam penelitian ini meliputi mean, minimum, masimum, dan standar deviasi. Pengolahan data untuk analisis deskriptif ini menggunakan program IBM SPSS Statistic 24. Deskripsi data masing-masing variabel secara rinci dapat dilihat dalam tabel berikut:

Tabel 4.1 Hasil Uji Statistik Deskriptif

\begin{tabular}{|c|c|c|c|c|c|c|}
\hline \multicolumn{7}{|c|}{ Descriptive Statistics } \\
\hline & $N$ & Range & Minimum & Maximum & Mean & Std. Deviation \\
\hline $\begin{array}{l}\text { Real Earnings } \\
\text { Management }\end{array}$ & 40 & 1,5175 &,- 0121 & 1,5054 & ,497393 &, 3758083 \\
\hline Dewan Komisaris & 40 & 4 & 2 & 6 & 4,28 & 1,281 \\
\hline $\begin{array}{l}\text { Proporsi Dewan } \\
\text { Komisaris Independen }\end{array}$ & 40 &, 1667 &, 3333 &, 5000 &, 390818 &, 0662467 \\
\hline Rapat Dewan Komisaris & 40 & 13,00 & 2,00 & 15,00 & 7,5250 & 3,84299 \\
\hline $\begin{array}{l}\text { Corporate Environmental } \\
\text { Disclosure }\end{array}$ & 40 & 9412 &, 0294 &, 9706 & ,333828 &, 2434067 \\
\hline Valid N (listwise) & 40 & & & & & \\
\hline
\end{tabular}

Sumber: pengujian dengan SPSS 24.00

\section{Uji Asumsi Klasik.}

Uji Normalitas. Uji normalitas berfungsi sebagai penguji untuk mengetahui kenormalan distribusi variabel dependen dan independen( Ghozali, 2018). Uji normalitas pada penelitian ini menggunakan uji kolmogorov smirnov dan analisis grafik, sebagai berikut:

a. Uji Kolmogorov Smirnov. Ghozali (2018) menjelaskan kriteria dalam uji kolmogorov smirnov jika dihasilkan taraf signifikansi lebih besar dari 0,05 atau 5\%, hal ini berarti data yang akan diolah memiliki distribusi normal. 


\section{Tabel 4.2 Hasil Uji Kolmogorov Smirnov}

One-Sample Kolmogorov-Smirnov Test

\begin{tabular}{llr} 
& & $\begin{array}{r}\text { Unstandardiz } \\
\text { ed Residual }\end{array}$ \\
\hline $\mathrm{N}$ & Mean & 40 \\
\hline Normal Parameters & Std. Deviation &, 0000000 \\
\hline Most Extreme Differences & Absolute &, 127 \\
\cline { 2 - 3 } & Positive &, 127 \\
\cline { 2 - 3 } & Negative &,- 085 \\
\hline Test Statistic &, 127 \\
\hline Asymp. Sig. (2-tailed) &, $104^{\circ}$ \\
\hline \multicolumn{2}{c}{ a. Test distribution is Normal. } \\
\multicolumn{2}{c}{ b. Calculated from data. } \\
\multicolumn{2}{c}{ c. Lilliefors Significance Correction. }
\end{tabular}

Sumber: pengujian dengan SPSS 24.00

Pengujian normalitas dengan uji Kolmogorov smirnov menunjukan bahwa data dihasilkan sebesar 0,104 artinya taraf signifikansi lebih besar dari 0,05 atau $5 \%$, hal ini berarti data yang akan diolah memiliki distribusi normal.

b. Chart Histogram. Uji normalitas menggunakan chart histogram dikatakan normal jika garis mengikuti kurva normal.

Tabel 4.3 Hasil Chart Histogram

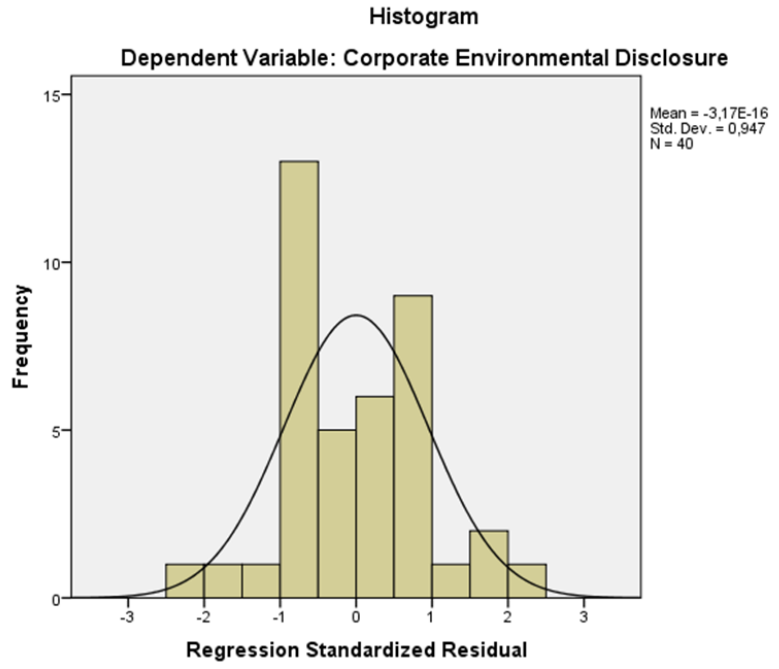

Sumber: pengujian dengan SPSS 24.00

Pengujian mengunakan chart histogram menunjukan bahwa pola mengikuti kurva dalam penelitian ini dapat diasumsikan memiliki distribusi normal.

c. Grafik Probability-Probability Plot (P-P plot). Pada grafik Normal P-P Plot, garis diagonal menunjukkan nilai normalitas yang diharapkan, Jika titik-titik berada atau dekat garis diagonal, maka data penelitian diinterpretasikan mempunyai distribusi yang normal. 


\section{Tabel 4.4 Hasil Chart Histogram}

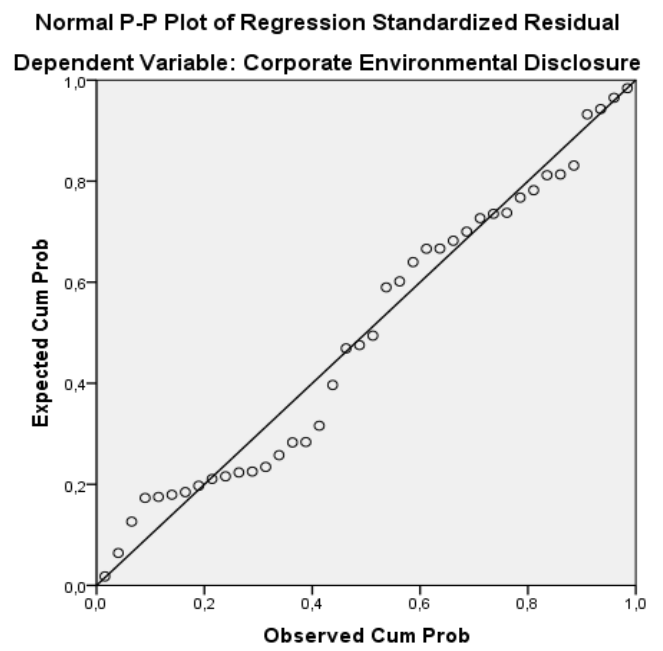

Sumber: pengujian dengan SPSS 24.00

Hasil pengujian ini menunjukan bahwa data yang digunakan dalam penelitian ini dapat diasumsikan memiliki distribusi normal karena sebaran data cenderung dekat dengan garis melintang seberti gambar diatas.

Uji Heteroskedastisitas. Bertujuan untuk menguji dalam model regresi terjadi kesamaan atau ketidaksamaan varian dari residual satu pengamatan kepengamatan yang lain (Ghozali, 2018).

\section{Tabel 4.5 Hasil Uji Heteroskedastisitas}

Scatterplot

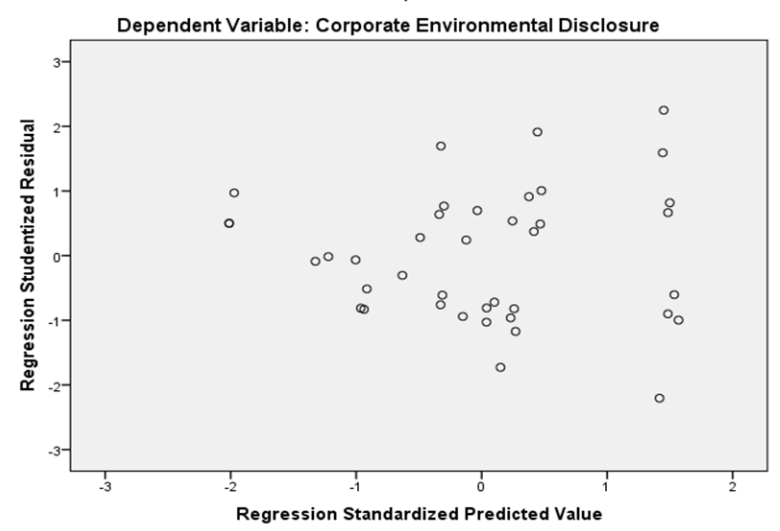

Sumber: pengujian dengan SPSS 24.00

Hasil pengujian ini menunjukan bahwa data yang digunakan dalam penelitian ini dapat diasumsikan terbebas dari heteroskedastisitas karena sebaran data yang terdapat dalam scatterplot di atas cenderung tidak membentuk suatu pola.

Uji Multikolinearitas. Uji Multikolinearitas berfungsi untuk mengetahui ada atau tidaknya penyimpangan asumsi klasik multikolinearitas dengan dibuktikannya adanya hubungan linear antar variabel independen dalam model regresi (Ghozali, 2018). 
Tabel 4.6 Hasil Uji Multikolinearitas

\begin{tabular}{|c|c|c|c|c|c|c|c|c|}
\hline \multicolumn{9}{|c|}{ Coefficients $^{a}$} \\
\hline & & \multicolumn{2}{|c|}{ Unstandardized Coefficients } & \multirow{2}{*}{$\begin{array}{c}\text { Standardized } \\
\text { Coefficients } \\
\text { Beta }\end{array}$} & \multirow[b]{2}{*}{$t$} & \multirow[b]{2}{*}{ Sig. } & \multicolumn{2}{|c|}{ Collinearity Statistics } \\
\hline \multicolumn{2}{|c|}{ Model } & B & Std. Error & & & & Tolerance & VIF \\
\hline \multirow[t]{5}{*}{1} & (Constant) &, 650 &, 280 & & 2,324 &, 026 & & \\
\hline & $\begin{array}{l}\text { Real Earnings } \\
\text { Management }\end{array}$ &,- 093 &, 087 &,- 144 & $-1,065$ &, 294 &, 760 & 1,315 \\
\hline & Dewan Komisaris &, 092 &, 024 & .484 & 3,764 &, 001 &, 836 & 1,196 \\
\hline & $\begin{array}{l}\text { Proporsi Dewan } \\
\text { Komisaris Independen }\end{array}$ & $-1,685$ & .515 &,- 459 & $-3,273$ & .002 & .704 & 1,420 \\
\hline & Rapat Dewan Komisaris &,- 001 & .008 &,- 011 & -.083 & .934 & .858 & 1,165 \\
\hline
\end{tabular}

Sumber: pengujian dengan SPSS 24.00

Hasil pengujian ini menunjukan bahwa data yang digunakan dalam penelitian ini dapat diasumsikan terbebas dari Multikolinearitas karena nilai yang tercantum dalam VIF tidak melebihi 10 dan nilai Toleransi di atas 0,1 .

Uji Autokorelasi. Berfungsi untuk menguji dalam model regresi linier ada atau tidak ada kolerasi antar kesalahan pengganggu pada periode $\mathrm{t}$ dengan kesalahan pengganggu pada periode $\mathrm{t}$ dengan kesalahan pengganggu pada periode $\mathrm{t}-1$ atau periode sebelumnya (Ghozali, 2018).

Tabel 4.7. Hasil Uji Autokorelasi

\begin{tabular}{|c|c|c|c|c|c|}
\hline \multicolumn{6}{|c|}{ Model Summary } \\
\hline Model & $\mathrm{R}$ & R Square & $\begin{array}{c}\text { Adjusted R } \\
\text { Square }\end{array}$ & $\begin{array}{l}\text { Std. Error of } \\
\text { the Estimate }\end{array}$ & $\begin{array}{l}\text { Durbin- } \\
\text { Watson }\end{array}$ \\
\hline 1 &, $718^{a}$ & .516 & 461 & 1787253 & 1,824 \\
\hline
\end{tabular}

Hasil pengujian ini menunjukan bahwa data yang digunakan dalam penelitian ini dapat diasumsikan terbebas dari adanya autokorealsi dikarenakan nilai Durbin-Watson yang terdapat dalam tabel model summary lebih besar dari nilai batas atas Durbin-Watson yang seharusnya. Nilai Durbin Watson (D) dalam penelitian ini sebesar 1,824 lebih besar dari nilai $\mathrm{DU}=1,72092$ atau 1,824 > 1,72092. Jika d > dU maka tidak terdapat autokorelasi.

Pengujian Hipotesis. Bagian ini berisi penjelasan penggunaan model regredi disertai indikator dalam pengukuran hipotesis yang digunakan. Persamaan analisis regresi linier juga harus dicantumkan dalam penelitian ini adalah sebagai berikut (contoh):

Uji Koefisien determinasi. Uji adjusted $\mathrm{R}^{2}$ digunakan untuk menguji kebenaran presidiksi dari pengujian regresi yang dilakukan, dengan cara mencari nilai koefisien determinasinya (Ghozali, 2018).

Tabel 4.8 Hasil Uji Koefisien determinasi

\begin{tabular}{|c|c|c|c|c|c|}
\hline \multicolumn{6}{|c|}{ Model Summary } \\
\hline Model & $R$ & R Square & $\begin{array}{l}\text { Adjusted R } \\
\text { Square }\end{array}$ & $\begin{array}{l}\text { Std. Error of } \\
\text { the Estimate }\end{array}$ & $\begin{array}{l}\text { Durbin- } \\
\text { Watson }\end{array}$ \\
\hline 1 & $.718^{a}$ & .516 & .461 & ,1787253 & 1,824 \\
\hline
\end{tabular}


Hal ini berarti bahwa 46,1\% corporate environmental disclosure dapat dijelaskan oleh real earnings management dan corporate governance dengan proksi ukuran dewan komisaris, proporsi dewan komisaris independen dan rapat dewan komisaris. Sedangkan sisanya 53,9\% dijelaskan oleh variabel-variabel yang lain di luar persamaan

Uji F. Berfungsi untuk menunjukkan apakah semua variabel independen atau bebas dalam model penelitian mempunyai pengaruh terhadap variabel dependen (Ghozali, 2018).

\begin{tabular}{|c|c|c|c|c|c|c|}
\hline \multicolumn{7}{|c|}{ Tabel 4.10 Hasil Uji F } \\
\hline Model & & $\begin{array}{l}\text { Sum of } \\
\text { Squares }\end{array}$ & df & Mean Square & $\mathrm{F}$ & Sig. \\
\hline \multirow[t]{3}{*}{1} & Regression & 1,156 & 3 & .385 & 12,022 & $.000^{\mathrm{b}}$ \\
\hline & Residual & 1,154 & 36 & .032 & & \\
\hline & Total & 2,311 & 39 & & & \\
\hline
\end{tabular}

Sumber: pengujian dengan SPSS 24.00

Hasil menunjukkan nilai yang lebih kecil daripada tingkat signifikansi yang telah di tentukan yaitu 0,05. Kesimpulannya bahwa corporate governance dengan proksi dewan komisaris, proporsi dewan komisaris dan rapat dewan komisaris secara bersama-sama berpengaruh terhadap corporate environmental disclosure.

Uji t. Uji hipotesis $\mathrm{t}$ berfungsi untuk melihat pengaruh secara individu variabel bebas terhadap varibael terikat. Menurut Ghozali (2018) Cara menukur uji hipotesis t dengan mengunakan signifikasi parameter individual, pengujian dilakukan dengan menggunakan tingkat signifikan sebesar $0,05(\alpha=5 \%)$.

\section{Tabel 4.9 Hasil Uji t}

\begin{tabular}{|c|c|c|c|c|c|c|c|c|}
\hline \multicolumn{9}{|c|}{ Coefficients $^{a}$} \\
\hline \multirow[b]{2}{*}{ Model } & & \multicolumn{2}{|c|}{ Unstandardized Coefficients } & \multirow{2}{*}{$\begin{array}{c}\text { Standardized } \\
\text { Coefficients } \\
\text { Beta }\end{array}$} & \multirow[b]{2}{*}{$t$} & \multirow[b]{2}{*}{ Sig. } & \multicolumn{2}{|c|}{ Collinearity Statistics } \\
\hline & & B & Std. Error & & & & Tolerance & VIF \\
\hline \multirow[t]{5}{*}{1} & (Constant) & 650 & 280 & & 2,324 & 026 & & \\
\hline & $\begin{array}{l}\text { Real Earnings } \\
\text { Management }\end{array}$ &,- 093 & 087 &,- 144 & $-1,065$ &, 294 &, 760 & 1,315 \\
\hline & Dewan Komisaris &, 092 & 024 & ,484 & 3,764 & 001 & 836 & 1,196 \\
\hline & $\begin{array}{l}\text { Proporsi Dewan } \\
\text { Komisaris Independen }\end{array}$ & $-1,685$ & .515 &,- 459 & $-3,273$ &, 002 &, 704 & 1,420 \\
\hline & Rapat Dewan Komisaris &,- 001 & 008 &,- 011 &,- 083 &, 934 & 858 & 1,165 \\
\hline
\end{tabular}

Sumber: pengujian dengan SPSS 24.00

Berdasarkan hasil penelitian di atas dapat disimpulkan bahwa variabel yang berpengaruh terhadap corporate environmental disclosure adalah dewan komisaris dan proporsi dewan komisaris independen. Hal ini dapat dilihat pada nilai signifikan (sig.) yang menunjukan hasil kurang dari 0,05. Real earnings management dan rapat dewan komisaris dengan nilai sig. lebih dari 0,05. Menunjukan real earnings management dan rapat dewan komisaris tidak memiliki pengaruh terhadap corporate environmental disclosure.

Real earnings management terhadap corporate environmental disclosure diperoleh bahwa hasil $\beta$ sebesar -0,093 dengan tingkat signifikan sebesar 0,294 berada lebih besar pada $\alpha=0,05$, sehingga hipotesis pertama ditolak. Hal ini dapat disimpulkan bahwa real earnings 
management tidak dapat dibuktikan berpengaruh terhadap corporate environmental disclosure.

Corporate governance menggunakan proksi dewan komisaris terhadap corporate environmental disclosure diperoleh bahwa hasil $\beta$ sebesar 0,092 dengan tingkat signifikan sebesar 0,001 berada tidak lebih besar dari $\alpha=0,05$ atau kurang dari $5 \%$, sehingga hipotesis kedua diterima. Nilai $\beta$ positif signifikan berarti bahwa semakin besar ukuran dewan komisaris akan semakin tinggi tingkat pengungkapan informasi lingkungan dalam annual report. Hal ini dapat disimpulkan bahwa corporate governance mengunakan proksi ukuran dewan komisaris berpengaruh positif terhadap corporate environmental disclosure.

Corporate governance menggunakan proksi proporsi dewan komisaris independen terhadap corporate environmental disclosure diperoleh bahwa hasil $\beta$ sebesar -1,685 dengan tingkat signifikan sebesar 0,002 berada kurang dari $\alpha=0,05$, sehingga hipotesis ketiga diterima. Nilai $\beta$ negatif menunjukan bahwa semakin kecil tingkat corporate governance dengan proksi proporsi dewan komisaris independen akan semakin tinggi tingkat pengungkapan informasi lingkungan dalam annual report. Hal ini dapat disimpulkan bahwa proporsi dewan komisaris berpengaruh negatif terhadap corporate environmental disclosure.

Corporate governance menggunakan proksi rapat dewan komisaris terhadap corporate environmental disclosure diperoleh bahwa hasil $\beta$ sebesar $-0,001$ dengan tingkat signifikan sebesar 0,934 berada lebih besar pada $\alpha=0,05$, sehingga hipotesis empat ditolak. Hal ini dapat disimpulkan bahwa rapat dewan komisaris dapat dibuktikan tidak berpengaruh terhadap corporate environmental disclosure.

\section{Simpulan dan Saran}

\section{Simpulan}

1. Real earnings management tidak berpengaruh terhadap corporate environmental disclosure. Perusahaan yang tidak ataupun melakukan real earnings management di dalam laporan keuangan perusahaan tidak akan mempengaruhi perusahaan untuk mengungkapkan tanggung jawab lingkungan perusahaan. Pengungkapan tersebut bukan untuk menutupi tindakan oportunis yaitu manajemen laba aktivitas rill yang dilakukan oleh perusahaan melainkan atas bentuk tanggung jawab lingkungan perusahaan akibat dari kegiatan usahanya.

2. Dewan komisaris terbukti berpengaruh terhadap corporate environmental disclosure. Dewan komisaris sebagai dewan tertinggi didalam internal perusahaan yang bertanggung jawab bagaimana semua tindakan dan kebijakaan perusahaan atas dasar keputusan dewan komisaris. Dewan komisaris akan mendorong perusahaan mendapat nilai atau citra baik terhadap steakholders maupun lingkungan masayarakat. Ukuran dewan komisaris mempengaruhi untuk mendorong melakukan pelaporan pengungkapan tanggung jawab lingkungan lebih transparent.

3. Proporsi dewan komisaris independen membuktikan adanya berpengaruh terhadap pengungkapan lingkungan. Proporsi dewan komisaris independen dalam jajaran dewan komisaris terhadap kinerja perusahaan kurang memberikan pengawasan untuk manajemen melakukan pengungakapan tanggung jawab lingkungan. Corporate governance terhadap corporate environmental disclosure tidak hanya dipengaruhi oleh jumlah komisaris independen tetapi juga keahlian, pengetahuan, latar belakang, dan 
perbedaan kompetensi dalam meningkatkan kualitas pengambilan keputusan pada tingkat dewan komisaris dimana tanggung jawab sosial lingkunagan dihubungkan.

4. Rapat dewan komisaris tidak berpengaruh terhadap corporate environmental disclosure. karena sering atau tidaknya rapat yang dilakukan oleh dewan komisaris tidak berdampak pada fungsi pengawasan yang efektif dan pengungkapan yang lebih luas. Pengawasan tersebut berfokus pada kenerja keuangan saja dan mengabaikan penungkapan tanggung jawab sosial termasuk lingkungan hidup.

\section{Saran}

1. Bagi Pemerintah: Pemerintah hendaknya mewajibkan peraturan secara tegas dan jelas mengenai praktik environmental disclosure pada perusahaan di Indonesia sehingga praktik tentang environmental disclosure di Indonesia semakin meningkat. Tidak hanya praktik yang telah dilakukan juga harus ada peraturan bukan hanya laporan yang bersifat sukarela tetapi mewajibkan adanya transparansi didalam annual report mengenai laporan environmental disclosure.

2. Bagi Penelitian Selanjutnya: Sebaiknya untuk penelitian selanjutnya memperluas sampel penelitian dengan meneliti sektor lain seperti manufaktur dan jasa agar membuktikan bahwa pengaruh real earnings management dan corporate governance terhadap corporate environmental disclosure. Penelitian selanjutnya disarankan menambahkan jumlah sampel dan memperpanjang periode tahun penelitian selama lebih dari 5 tahun. Penelitian selanjutnya dapat mengembangkan penelitian ini mengukur corporate governanace dengan proksi yang lebih luas tidak hanya pada dewan komisaris tetapi komite audit, kondisi keuangan dan non keuangan, manajemen, dan lain-lain agar mendapatkan hasil yang lebih komprehensif mengambarkan corporate governanace. Penelitian selanjutnya juga menambahkan variabel lainnya diluar variabel real earnings management dan corporate governance dalam penelitian ini, agar mendapatkan hasil yang lebih komprehensif mengenai faktor-faktor yang mempengaruhi environmental disclosure.

\section{DAFTAR PUSTAKA}

Anggraini, Fr Reni Retno. (2006). Pengungkapan Informasi Sosial dan Faktor-faktor yang Mempengaruhi Pengugkapan Informasi Sosial dalam Laporan Keuangan Tahunan (Study Empiris pada Perusahaan-perusahaan yang Terdaftar di Bursa Efek Jakarta). Dalam Prosiding Simposium Nasional Akuntansi IX. Padang

Ardiansyah, Beni. (2014). Opini: Daerah Aliran Sungai di Bengkulu Rusak Akibat Pertambangan Terbuka. diakses 28 September 2018. https://www.mongabay.co.id/2014/12/09/opini-daerah-aliran-sungai-di-bengkulurusak-akibat-pertambangan-terbuka/.

Ardillah, Kenny. (2018). Pengaruh Real Manipulation Dalam Memoderasi Corporate Environmental Disclosure Dan Corporate Financial Performance. National Conference of Creative Industry: Sustainable Tourism Industry for Economic Development. diakses pada tanggal 15 Juli 2019. https://www.researchgate.net/publication/328832809.

Brick, Ivan E. \& Chidambaran, N.K., Board Meetings. (2007). Committee Structure, and Firm Performance. Available at. diakses pada tanggal 15 Juli 2019. SSRN: https://ssrn.com/abstract=1108241. 
Deegan, C. (2014 ). Financial Accounting Theory, 4th edn., Australia: Mcgraw-Hill. ISBN: 9780071013147.

Effendi, B., Uzliwati, L., \& Yulianto, A. S. (2012). Pengaruh Dewan Komisaris Terhadap Environmental Disclosure Pada Perusahaan Manufaktur yang Listing di BEI Tahun 2008-2011. Simposium Nasional Akuntansi XV.

Effendi, B. (2017). Ukuran Perusahaan, Jumlah Rapat Dewan Komisaris dan Environmental Disclosure di Indonesia. At Negotium Procuratio: Jurnal Bisnis dan Manajemen, $3(2), 13-25$.

Effendi, B. (2018). Dapatkah Dewan Komisaris Melejitkan Praktik Environmental Disclosure di Indonesia?. Konferensi Akuntansi Banten I, Serang. IAI KaPd.

Effendi, B. (2018). Ukuran Perusahaan, Dewan Komisaris dan Environmental Disclosure. JRA Tirtayasa: Jurnal Riset Akuntansi, 3(1), 1-19.

Effendi, B. (2019). Pengaruh Implementasi Program Corporate Social Responsibility Terhadap Kepuasan Masyarakat (Studi Kasus pada PT. Krakatau Steel, Tbk. di Kota Cilegon). Dalam Proceeding FRIMA (Festival RisetIlmiah Manajemen dan Akuntansi). Bandung. STIE STEMBI Bandung.

Effendi, B. (2020). Profesional Fee, Pergantian Chief Executive Officer (CEO), Financial Distress dan Real Earnings Management. Jurnal Ilmiah Akuntansi dan Bisnis, 4(2), $105-120$.

Forum for Corporate Governance in Indonesia. (2005). Seri Tata Kelola Perusahaan (Corporate Governance), Jilid II; Peranan Dewan Komisaris dan Komite Audit dalam Pelaksanaan Corporate Governance, diakses pada tanggal 18 Oktober 2018.http://www.fcgi.or.id.

Frendy dan Kusuma, Indra Wijaya. (2011). The Impact of Financial, Non-Financial, and Corporate Governance Attributes on The Practice of Global Reporting Initiative (GRI) Based Environmental Disclosure. Gadjah Mada International Journal of Business.Vol. 13, No. 2 (May - August 2011): 143 - 159.

Ghozali, Imam. (2018). Ekonometrika Teori, Konsep dan Aplikasi dengan Program IBM SPSS 24. Semarang : BPFE Universitas Diponegoro.

Gray et. al. (1987). Social and Environmental Disclosure and Corporate Characteristic: A Research Note and Extension. Journal of Cusiness Fianance and Accounting, 28(3), 327-356

Haniffa dan Cooke. (2005). The Impact of Culture and Governance on Coporate Social Reporting. Journal of Accounting and Public Policy, 391-430.

Ikatan Akuntansi Indonesia. (2014). Pernyataan Standar Akuntansi Keuangan No. 1 : Penyajian Laporan Keuangan. Jakarta : Salemba Empat.

Ismalia, N. ,Kurniawan dan Setiadi, Iwan. (2018). Corporate Governance Dan Karakteristik Perusahaan Terhadap Manajemen Laba. JIA\&P: Jurnal Ilmiah Akuntansi dan Pariwisata, 1(2), 1-18.

Istianingsih. (2016). Deteksi Manajemen Laba Melalui Discretionary Revenue dan Aktifitas Riil : Implikasi Penerapan Good Corporate Governance, 4(3).

Jensen, Michael C. dan William H. Meckling. (1976). Theory of the Firm: Managerial Behaviour, Agency Costs and Ownership Structure. Journal of Financial Economics, 3(4), 305-360.

Kementrian Lingkungan Hidup. (2014). Peraturan Menteri Lingkungan Hidup Republik Indonesia Nomor 7 Tahun 2014 Tentang Kerugian Lingkungan Hidup Akibat Pencemaran Dan/Atau Kerusakan Lingkungan Hidup.

Komite Nasional Kebijakan Governance. (2006). Pedoman Umum Corporate Governance Indonesia. Jakarta. 
Lu, Y \& Abeysekera, I. (2014). Stakeholders' power, corporate characteristics, and social and environmental disclosure. Journal of Cleaner Production, 64(1), 426-436.

Murwaningsari, E. (2009). Hubungan Corporate governance, Corporate Social Responsibilities dan Corporate Financial Performance Dalam Satu Continuum. Jurnal Akuntansi dan Keuangan, 11(1), 30-41.

Nofianti, N., Uzliawati, L \& Sarka. (2015). Pengaruh Corporate Governance terhadap Environmental Disclosure dengan Environmental Performance sebagai Variabel Moderating. Jurnal Trikonomika, 14(1), 38-46.

Nuraini, N., Effendi, B., \& Setiadi, I. (2018). Corporate Governance dan Environmental Disclosure. JIA\& P: Jurnal Ilmiah Akuntansi dan Pariwisata, 1(2), 19-30.

Organisation for Economic Co-operation and Development. (2015). The OECD Guidelines on Corporate Governance of State-Owned Enterprises. https://www.oecd.org/daf/ca/guidelines-corporate-governance-soes.htm

Otoritas Jasa Keuangan. (2014). Peraturan Otoritas Jasa Keuangan Nomor 33/POJK.04/2014 tentang Direksi dan Dewan Komisaris Emiten atau Perusahaan Publik.

Otoritas Jasa Keuangan. (2016). Surat Edaran Otoritas Jasa Keuangan Nomor 30 /SEOJK.04/2016 tentang Bentuk Dan Isi Laporan Tahunan Emiten Atau Perusahaan Publik.

Perwita, Veronika, KD. (2009). Pengaruh Environmental Disclosure terhadap Reaksi Pasar dan Nilai Perusahaan. Skripsi. Universitas Diponegoro, Semarang.

Prior, D., J. Surroca dan J. A. Tribo. (2008). Are Socially Responsible Managers Really Ethical? Exploring the Relationship Between Earnings Manajegemnt and Corporate Social Responsibility. Jurnal Compilation, 16(3), 160-177.

Republik Indonesia. (2007). Undang-Undang No. 40 Tahun 2007 tentang Perseroan Terbatas.

Republik Indonesia. (2009). Undang-Undang No. 4 Tahun 2009 tentang Pertambangan Mineral dan Batubara.

Republik Indonesia. (2009). Undang-Undang No. 32 Tahun 2009 tentang Perlindungan dan Pengelolaan Lingkungan Hidup.

Sekarwigati, M. \& Effendi, B. (2019). Pengaruh Ukuran Perusahaan, Profitabilitas, dan Likuiditas terhadap Corporate Social Responsibility Disclosure. STATERA: Jurnal Akuntansi dan Keuangan, 1(1), 16 - 33.

Kothari, S.P., Mizik, N., \& Roychowdhury S. (2012). Managing for the moment : The Role of Real Activity versus Accruals Earnings Management in SEO Valuation. Accounting Review, 91(2), 559-86.

Sembiring, Carolyn Lukita \& Nahumury, Joicenda. (2018). Mitigasi Manipulasi Laba Aktivitas Rill dengan Keefektifan Internal Governance Studi pada Perusahaan Publik di Indonesia. Berkala Akuntansi dan Keuangan Indonesia, 3(2), 1-22.

Scott, William. (2013). Financial Accounting Theory. 3rd Edition. New Jersey : Prentice-Hall Inc.

Setyastrini, Ni Luh Putri \& Wirajaya, I Gde Ary. (2017). Intensitas Pengungkapan Corporate Social Responsibility: Pengujian Dengan Manajemen Laba Akrual dan Riil. E-Jurnal Akuntansi Universitas Udayana, 19(1), 337-366.

Setyawan, Hendri \& Kamilla, Puteri. (2015). Impact of Corporate Governance on Corporate Environmental Disclosure: Indonesian Evidence. Economies, Humanities, and Management. https://icehm.org/upload/2392ED815026.pdf

Stubben, Stephen R. (2010). Discretionary Revenues as a Measure of Earnings Management, American Accounting Association: The University of North Carolina at Chapel Hill.

Sugiyono. (2016). Metode Penelitian Kuantitatif, Kualitatif dan R\&D. Bandung: PT Alfabet. 
Sun, Nan, Aly Salama, Khaled Hussainey, dan Murya Habbash. (2010). Corporate Environmental Disclosure, Corporate governance and Earnings Management. Managerial Auditing Journal, 25(7), 679-700.

WALHI. (2018). Putusan Jauh dari Asas Keadilan, Koalisi Desak Negara Lakukan Upaya Banding. diakses 28 September 2018. http: //www.walhi.or.id/

Waryanto. (2010). Pengaruh Karakteristik Good Corporate Governance (GCG) terhadap Luas Pengungkapan Corporate Social Responsibility (CSR) di Indonesia. Skripsi Akuntansi. Universitas Diponegoro.

Wisnantiasri, Sila Ninin \& Narsa, I Made. (2014). Hubungan Manajemen Laba Dengan Menggunakan Manipulasi Aktivitas Riil Dan Kinerja Operasi. Jurnal Akuntansi Aktual, 2(4), 297-311

Yateno \& Sari, Gustin Padwa. (2016). Penguji Manipulasi Laba Real Pada Pengungkapan Corporate Social Responsibility. Akuisis Jurnal Akuntansi, 12(2).

Zaky M., Muchamad Syafruddinb, Dul Muidc, \& St. Dwiarso Utomo. (2017). Manajemen Laba, Pengungkapan Lingkungan Perusahaan dan Mekanisme Tata Kelola Perusahaan. Jurnal Dinamika Akuntansi dan Bisnis, 4(1), 57-72.

Global Reporting International (GRI). Diakses tanggal 18 Oktober 2018. www.globalreporting.org.

Bursa Efek Indonesia. Diakses tanggal 18 Oktober 2018. www.idx.co.id .

Universitas Stanford. http://www.standford.edu. 